\title{
Epithelioid Neurofibroma
}

National Cancer Institute

\section{Source}

National Cancer Institute. Epithelioid Neurofibroma. NCI Thesaurus. Code C6558.

A rare neurofibroma with epithelioid morphology. 